\title{
O posto e o pressuposto: Ruy Fausto e a ideia de crítica imanente em Marx
}

\author{
The posited and the presupposed: Ruy Fausto and the Idea of \\ Immanent Critique in Marx
}

\author{
Luiz Repa \\ luizrepa@usp.br \\ (Universidade de São Paulo, São Paulo, Brasil)
}

\begin{abstract}
Resumo: 0 artigo pretende desenvolver a ideia de crítica imanente em Marx recorrendo aos estudos de Ruy Fausto sobre a lógica das noções de posição e pressuposição. Pretendo mostrar, em primeiro lugar, que o jogo entre posição e pressuposição se desenha em Ruy Fausto em dois sentidos interligados, um lógico-ontológico e um especificamente político, o que permite discernir como a crítica opera em um sentido normativo não descolado da efetividade. Em um segundo momento, procuro esboçar como as figuras da posição e da pressuposição se entrelaçam, mais especificamente como a posição cria um campo de pressuposições objetivas que sustentam sua significação, de modo que a crítica não se atém apenas à imanência do posto mas também do pressuposto.
\end{abstract}

Palavras-chave: crítica imanente; posição; pressuposição; lógica; política.

\begin{abstract}
The article intends to develop the idea of immanent critique in Marx's thought using Ruy Fausto's studies on the logic of the notions of position and presupposition. First, I intend to show that the play between position and presupposition stands out in two interconnected senses, a logicalontological and a specifically political one, which allows us to discern how critique operates in a normative sense not detached from effectiveness. In a second moment, I try to outline how the figures of position and presupposition intertwine, more specifically how the position creates a field of objective presuppositions that support its meaning in such a way that the critique is attached not only to the immanence of position but also to the immanence of presupposition.
\end{abstract}

Keywords: immanent critique; position; presupposition; logic; politics.

DOI: http://dx.doi.org/10.11606/issn.2318-9800.v26i2p95-110

$\mathrm{Na}$ origem desse escrito se encontra a tentativa de responder a duas perguntas relativas à natureza do conceito de crítica em Marx, a saber: em que medida é possível interpretar a crítica marxiana da economia política como uma forma de crítica imanente, e, no interior desse questionamento, qual seria o papel das categorias de posição e pressuposição tal como Ruy Fausto buscou concebê-las ao longo de sua investigação sobre o sentido da dialética?

As duas questões abrangem uma série considerável de dificuldades, a começar pelo envolvimento de Marx com a dialética hegeliana, de cuja complexidade o projeto histórico-filosófico de Ruy Fausto é um dos testemunhos mais caros de que dispomos, exibindo uma envergadura que desaconselha abordagens mais gerais, necessariamente 
insuficientes (Fausto, 1993). Por isso, os pontos de interrogação devem se situar em níveis um pouco mais específicos: ao criticar as categorias da economia política clássica, Marx daria continuidade, de modo certamente distinto, ao tipo de crítica que Hegel entabula na introdução de sua Fenomenologia do espírito, em particular no que diz respeito ao critério posto da crítica? Em consequência disso, esse tipo de crítica lançaria, como Ruy Fausto desdobra, um jogo de posição e pressuposição que estrutura o discurso dialético em geral e o marxiano em particular?

Hegel defende na Fenomenologia do espírito que o movimento crítico tem de partir dos critérios postos com ou pelo próprio objeto criticado, o seu conceito de verdadeiro ou ainda, se for o caso, de bom, para não pagar o preço de uma exterioridade inaceitável e de todo modo inócua. 0 objeto, o saber fenomênico no caso da Fenomenologia, "dá o seu critério", de sorte que a investigação sobre ele se torna uma "comparação" do objeto consigo mesmo, do conceito que tem sobre a verdade e a efetividade desse saber, mais exatamente uma observação atenta dessa comparação que a cada vez se desfecha na destruição e transformação do próprio objeto, na sua “negação determinada”, o que significa a emergência de um novo critério:

$\mathrm{Na}$ medida em que a consciência considera, junto a seu objeto, que seu saber não lhe corresponde, tampouco o objeto se sustenta; ou o critério do exame se altera se aquilo do que ele devia ser o critério não passa no exame; e o exame não é apenas um exame do saber, mas também de seu critério (Hegel, PhG, Werke, III, p. 78).

De acordo com Hegel, a crítica imanente não é afirmação dos critérios dados na eventual percepção de uma falha; a experiência do erro já envolve uma transformação na normatividade que serve de padrão de medida e, dessa maneira, a crítica se torna também a investigação genética do novo critério (cf. De Boer, 2012; Becker, 2018, Repa, 2019).

Por sua vez, a Ciência da lógica não vai entender de outro modo a lógica objetiva, o que ela supõe ser, à diferença da noção kantiana, a "verdadeira crítica" das determinações metafísicas, "sem considerá-las segundo a forma abstrata da aprioridade versus o a posteriori, mas sim em seu conteúdo particular" (WL, Werke, V, p. 62). A crítica não se limita, assim, às formas de consciência ou de representação do mundo por parte da consciência, mas se estende às formas lógicas de apresentação do mundo, como revela o seguinte adendo da Enciclopédia:

é preciso que a atividade das formas do pensamento e sua crítica sejam unificadas no conhecimento. As formas do pensamento têm de ser consideradas em si e por si mesmas; elas são o objeto e a atividade do próprio objeto; elas se examinam a si mesmas, precisam determinar nelas mesmas seu limite e sua insuficiência. Nesse caso, esta é aquela atividade do pensamento que, como dialética, (...) não deve ser considerada como do exterior, mas antes como imanente a elas (Enz, Werke, VIII, § 41). 
A crítica imanente é, para usar uma expressão adorniana, o próprio "procedimento da dialética" (Adorno, 2015, p. 36): ater-se ao que o objeto diz de si mesmo para ali, tomando-o ao pé da letra, descobrir suas limitações, contradições e impulsos de transformação. ${ }^{1}$ De acordo com o registro de Hans-Georg Backhaus, o próprio Adorno não teria dúvida de que o projeto crítico marxiano se deixaria descrever em proximidade com a concepção hegeliana, determinando o cerne do discurso a ser tomado literalmente:

A teoria liberal é confrontada com sua própria pretensão, referida ao ato de troca. "Vós dizei que equivalentes são trocados, que ocorre uma troca livre e justa, eu vos tomo pela palavra, agora queremos ver como isso se apresenta". Isso é crítica imanente (Adorno/Backhaus, 1997, p. 505).

Habermas segue a mesma interpretação ao dizer que, "para a finalidade de sua prática de pesquisa, Marx pôde se contentar em tomar ao pé da letra e criticar de modo imanente o conteúdo normativo das teorias burguesas dominantes" (Habermas, 2014a, p. 27), no que a "ideologia básica da troca justa" teria um papel chave (Habermas, 2014b, p. 103).

Nessa perspectiva, a crítica imanente marxiana tomaria ao pé da letra os componentes que formam a autocompreensão da sociedade burguesa como uma sociedade de mercado baseada em troca de equivalentes e, por isso, como uma sociedade justa em si mesma, para a partir deles, como únicos critérios aceitáveis, demonstrar como caem no oposto do que pregam ao ser seguidos de maneira estrita. ${ }^{2}$ De certo modo, a passagem que vai da circulação de mercadorias ao processo de produção poderia ser visto como o exame do alcance dos princípios normativos que a sociedade burguesa estabelece na primeira esfera. Como dizem os Grundrisse, esses princípios são postos com a relações de troca, de modo que esfera da circulação envolveria, como sua base real, uma série de "direitos" a título de "expressões

10 que não significa dizer que a crítica imanente adorniana simplesmente dá continuidade à matriz hegeliana ou ao modelo marxiano de crítica imanente, buscado aqui. Sobre isso, cf. Nobre, 1998, Repa, 2011.

2 Deixo de lado aqui os projetos críticos de Marx em seu período de juventude. Cabe, no entanto, uma observação geral. A partir dos estudos de Seyla Benhabib sobre os fundamentos da teoria crítica (1986, p. 34 ss.), diversos autores dessa tradição, como Stahl, Celikates e Jaeggi, têm visto nos escritos que antecedem os Manuscritos de Paris, sobretudo a carta a Ruge de setembro de 1843, as origens do conceito de crítica imanente em Marx (cf. Zaventtor, 2020, p. 12 ss.). Há bons motivos para isso, já que Marx defende então, veementemente, o princípio de "não antecipar dogmaticamente o mundo, mas somente encontrar o mundo novo a partir da crítica ao antigo". Contudo, vale lembrar que as palavras finais da carta: "Todo nosso fim não pode consistir em nada mais, como é também o caso da crítica de Feuerbach à religião, do que colocar as questões religiosas e políticas na forma humana autoconsciente" ((MEW, 1, pp. 344-345). A crítica se delineia como uma crítica da alienação do ser genérico, cuja registro antropológico vai muito além do que a crítica imanente que Marx passa a desenvolver posteriormente nos termos da crítica da economia política. Nesse aspecto, o marxismo uspiano poderia orientar melhor a visão de conjunto sobre o desdobramento da crítica imanente em Marx, apesar das diferentes leituras sobre a presença da antropologia feuerbachiana em Marx (cf. Giannotti, 1965/1985; Fausto, 1983/1987d). 
idealizadas" correspondentes (Mega-2, II/1, p. 168). Porém, a formulação mais consagrada desses princípios postos pela esfera da circulação se encontra, sem dúvida, no primeiro tomo d'O capital, em que se prepara a mencionada passagem para a esfera da produção:

A esfera da circulação ou da troca de mercadorias, dentro de cujas barreiras se movem a compra e a venda de força de trabalho, foi de fato um verdadeiro éden dos direitos inatos do homem. $\mathrm{O}$ que aqui domina é unicamente Liberdade, Igualdade, Propriedade e Bentham. Liberdade! Pois comprador e vendedor de uma mercadoria, por exemplo, da força de trabalho, são determinados apenas por sua livre vontade. Contratam como pessoas livres, juridicamente de mesmo nível. O contrato é o resultado final, no qual suas vontades se dão uma expressão jurídica em comum. Igualdade! Pois eles se relacionam um com o outro apenas como possuidores de mercadorias e trocam equivalente por equivalente. Propriedade! Pois cada um dispõe apenas sobre o seu (MEW 23, pp. 189-190)

A partir do momento em que se passa à esfera da produção, à transformação do dinheiro como meio de circulação em capital, em valor que se valoriza, até chegar ao processo de acumulação enquanto tal, a liberdade dos participantes do contrato na relação de troca, sua igualdade formal, o direito de propriedade e, enfim, a equivalência da troca - todos esses elementos se "intervertem" no seu contrário, como Ruy Fausto quer salientar desde o início de sua série de investigações, sem que eles sofram qualquer violação externa. Ao contrário, é por que essas regras são seguidas de maneira estrita que elas intervertem no seu oposto, que elas sofrem uma violência cometida por elas mesmas:

Sem que se faça violência à lei de apropriação das economias mercantis em geral, pelo contrário, uma vez estabelecidas as condições que permitem a sua manifestação mais completa (...), esta lei (a lei da apropriação pelo trabalho e pela troca de equivalentes) fazendo, de certo modo, violência a si mesma, se interverte no seu contrário. E assim se poderia afirmar - a conclusão que nos interessa - que, estabelecida a continuidade das voltas do capital que supõe a teoria da acumulação, a liberdade (dos contratantes, do operário em particular) se interverte em não-liberdade (a liberdade se torna uma aparência), e a propriedade, ou antes, o princípio de propriedade se interverte em princípio de não-propriedade (Fausto, 1983/1987a, p. 50)

Embora o conceito de crítica imanente não seja posto por Ruy Fausto no desdobramento de suas investigações, pela passagem se pode constatar como seu interesse pela interversão dos princípios normativos burgueses no seu oposto se coaduna com aquela ideia básica de crítica imanente derivada de Hegel: os princípios fazem violência a si mesmos ao serem seguidos sem violência, sem interferência a partir de uma dimensão normativa exterior. No entanto, Ruy Fausto ressalta e elabora elementos fundamentais que serviriam para destacar a lógica dessa crítica imanente. Eu me refiro às noções de posição e pressuposição a partir das quais ele pretende compreender o sentido do discurso marxiano.

De acordo com a hipótese desse ensaio, pode-se dizer, com base na 
interpretação de Fausto sobre o discurso marxiano, que a normatividade posta pelas relações de troca (equivalência, liberdade formal, igualdade jurídica, direito de propriedade) pressupõe concepções mais amplas que, ao serem negadas, a afetam inteiramente. Os conceitos mais amplos de liberdade, igualdade e propriedade são ao mesmo tempo pressupostos e negados pelos conceitos burgueses correspondentes. A negação mais estrita dos pressupostos conduz, no entanto, à perda de significação, à interversão no oposto. Pretendo mostrar, em primeiro lugar, que o jogo entre posição e pressuposição se desenha em Ruy Fausto em dois sentidos interligados, um lógicoontológico, outro propriamente político, que permitem distinguir como a crítica opera em um sentido normativo não descolado da efetividade. Em um segundo momento, procuro esboçar como as figuras da posição e da pressuposição se entrelaçam, mais especificamente, como a posição cria um campo de pressuposições objetivas que sustentam sua significação, de modo que a crítica não se atém apenas à imanência do posto, mas também do pressuposto.

0 contexto maior em que se inserem as considerações de método articuladas por Ruy Fausto é determinado desde cedo pelo debate sobre o humanismo que Althusser desencadeou ao propor o corte epistemológico no pensamento de Marx, entre a fase de juventude, filosófica, antropológica e “ideológica”, e a fase dita "científica", marcada pela emergência do materialismo histórico (Althusser, 1965/1979; Giannotti, 1965/1985; Fausto, 1983/1987e, 1983/1987d)). ${ }^{3}$ Ruy Fausto vai defender que a descontinuidade “indiscutível" entre o período de juventude e o de maturidade é de natureza lógico-ontológica (1983/1987e, 227): não há um corte epistemológico no sentido de que Marx passa a construir um discurso científico em detrimento do discurso filosófico, mas antes um modo de exposição em que o conteúdo metafísico da primeira fase, às vezes pressuposto, às vezes rejeitado, passa a ser exposto como uma realização do modo de produção capitalista, ou seja, como posto: a sociedade tem de ser exposta em termos metafísicos por um princípio científico como exposição mais fiel ao real (Fausto, 1983/1987b, p. 100; 1987a, p. $47 ; 1993$, p. 44), no que converge até certo ponto com a rejeição de José Arthur Giannotti à linha althusseriana (Giannotti, 1968/1980, p. 90 ss.). ${ }^{4}$

Essa via de interpretação tem implicações diretas para o uso das categorias de posição e pressuposição, em dois sentidos diferentes, que vão além das coordenadas

3 Sobre os antecedentes dessa incursão metodológica, envolvendo reflexões de método mas também considerações sobre as possibilidades revolucionárias no contexto brasileiro, cf. Arantes, 1994, p. 292 ss.

4 Se Ruy Fausto e Giannotti representam a leitura do corte lógico, embora o primeiro busque também acentuar uma certa continuidade (1983/1987e, 1983/1987d), Michael Löwy defenderá que a ruptura com a antropologia feuerbachiana é antes de tudo de natureza política. Cf. 2012, p. 128 ss.) 
histórico-filosóficas iniciais do debate e se estendem às injunções da virada do século. Em um primeiro sentido, que chamo aqui de "lógico-ontológico", trata-se de mostrar que a exposição das categorias da economia política em Marx busca determinar um movimento por meio do qual o sujeito real - o capital - é posto de tal modo que se torna posição que põe, e mais ainda: põe todos os seus pressupostos como posições de si mesmo e é este movimento mesmo de autoposição que o caracteriza como sujeito (Fausto, 1983/1987c, p. 188). ${ }^{5}$ Daí que a percepção mais realista da realidade capitalista seria o reconhecimento de configurações teológicas e metafísicas, da metafísica do real, que são determinadas pelo movimento de autoconstituição e autorreprodução do capital como sujeito.

Por outro lado, em um segundo sentido, que denomino "político", as figuras da posição e pressuposição trazem implicações crítico-normativas importantes, que permitem a Ruy Fausto não ter de pagar o preço da crítica ao antropologismo com uma postura anti-humanista como a defendida por Althusser e politicamente corporificada pelo stalinismo (no que mais tarde haveria, a seus olhos, também uma proximidade com a crítica de Giannotti ao humanismo do jovem Marx, repercutindo em suas supostas tendências à Realpolitik). ${ }^{6}$ Se o humanismo pode ser descrito como a posição do homem que no capitalismo o condena à sua interversão - o "humanismo se interverte em anti-humanismo" (Fausto, 1983/1987a, p. 32) - o anti-humanismo não resulta em outra coisa do que ele mesmo. Trata-se antes de negar a posição do homem para que ele "não se negue a si próprio" (1983/1987a, p. 33), sem ter de assumir a negação do homem, a violência, como princípio. ${ }^{7}$ Com isso, coloca-se

5 Também nesse aspecto se observa a convergência com a apreensão giannottiana do texto marxiano, de acordo com a distinção, presente nos Grundrisse, entre história contemporânea, o desenvolvimento categorial de um sistema, e a história de formação, do vir a ser dos fenômenos: "Marx mostra que não há nenhum pressuposto ao sistema que sobreviva se não for resposto por ele, que põe as condições de sua própria realização" (Giannotti, 1968/1980, 98).

6 Nesse último ponto, Ruy Fausto agudiza sua distância em relação a Giannotti, a qual não podemos aprofundar aqui, embora diga respeito ao cerne do assunto: "o que me parece caracterizar no fundo a filosofia de Giannotti: só o que é posto conta, para o pressuposto não há lugar visível. Sem dúvida, para a dialética o posto é outra coisa e em geral 'mais' do que o pressuposto; é o humanismo que apaga as diferenças. Mas para ela, o pressuposto vale, plenamente se se quiser, embora como pressuposto" (Fausto, 2002, 41). Tampouco podemos desdobrar a importante observação de Paulo E. Arantes sobre o déficit político que desde sempre Ruy Fausto enxergava em Althusser e Giannotti: "tanto na versão positivista dos althusserianos quanto na sua contrapartida ontológica giannottiana não havia lugar para a política” (Arantes, 1994, p. 306).

7 Posteriormente, Ruy Fausto vai determinar (ou corrigir) mais concretamente o argumento: se a não-violência se compromete com a violência, e a violência posta só leva a ela mesma, a violência só pode se legitimar como contraviolência, "afetada", portanto, de não-violência, e, além disso, depende dos contextos políticos concretos: "Não se trata em absoluto de banir toda legitimação da violência como contraviolência (pensemos na resistência contra os poderes totalitários), mas o fato de que há violência no interior da ordem burguesa não justifica mais o apelo à revolução violenta. 0 que afirmo está ligado à ideia de uma relativa autonomia da instituição democrática, e à de que ele representa um progresso" $(2002,21)$. Se é assim, cabe perguntar se a posição da democracia, mesmo que formal, estaria condenada à lógica da posição e interversão tal como a liberdade ou a propriedade, os exemplos mais recorrentes em Ruy Fausto. 
também a exigência de que o discurso dialético traga sempre consigo "zonas de sombra” (1983/1987a, p. 35), "halos de significações obscuras” (1987b, p. 149), já que ele não pode pôr os princípios para não querer vê-los perdidos na posição. Dessa maneira, não cabe à crítica pôr um princípio normativo, como o homem e noções fundamentais correlatas (a liberdade, a igualdade e mesmo a propriedade) para que não caia na perversão que é própria à posição (1983/1987a, p. 34). Mas tampouco se trata da tentativa inversa de renunciar aos princípios normativos, como que em um positivismo extremado, incapaz de sair de si mesmo.

Esses dois sentidos - "lógico-ontológico" e "político" - dos operadores "posição e pressuposição" se inter-relacionam de modo intricado nas investigações de Ruy Fausto sobre o discurso marxiano, mas se vinculam a objetivos diferentes. No primeiro sentido, ele pretende apreender a lógica da constituição do objeto, do capitalismo enquanto modo de produção voltada à reprodução do capital - embora também se aplique diferentemente às formas antecedentes de produção -, ao passo que o segundo quer traçar a lógica da crítica desse objeto. Eles convergem na medida em que o capital como sujeito “pleno" posto reverbera como negação completa do homem enquanto sujeito pressuposto: "O discurso teórico marxista em sentido estrito tem como objeto central não os predicados do sujeito pressuposto 'homem', mas o sujeito real 'capital', cujos predicados - suportes - reais são os predicados (negações) ‘do’ sujeito pressuposto homem” (Fausto, 1983/1987a, p. 31). A explicitação contínua de como "o valor se torna aqui sujeito de um processo", de como vai de "substância" posta para sujeito que se põe, indica assim a impossibilidade de garantir uma instância objetiva para o humanismo (cf. 1983/1987c, p. 188.

Por outro lado, no segundo sentido, a própria posição ou a rejeição da posição, no nível do discurso, veem-se condenadas à interversão. Não é possível "pôr" o homem uma vez que ele é negado como sujeito pressuposto. Mas nem por isso essa pressuposição deve se tornar posição de que parte a crítica, como no humanismo reformista, em que a não violência acaba tolerando a violência. "Porque 'pôr' (setzen, poser) num universo inumano (o do capitalismo e em geral o de todo o 'pré-socialismo') implica aceitar - se tornar cúmplice d' - este universo inumano". (1983/1987a, p. 32). Daí resulta que a crítica tem de recusar o fundamento "homem" para que ele não se negue, tem de acolher a ideia de "não posição" (p. 34), mas, ao mesmo tempo, conferir o que as posições reais nos dizem a respeito das pressuposições de algum modo desejáveis ou incontornáveis.

Se o homem não é plenamente posto, se ele é ainda pressuposto, como acontece na pré-história segundo a acepção marxiana (mas não do mesmo modo entre o capitalismo e o pré-capitalismo), então todo juízo sobre ele é um juízo de reflexão, em certa convergência com a lógica hegeliana da essência (1987a, p. 84): o sujeito reflete, passa “no" predicado, que é negação do sujeito enquanto 
sujeito (“o homem é o operário") (cf. também 1987a, p. 20). O predicado não é propriamente determinação do sujeito, mas sua negação enquanto sujeito. Somente o predicado é posto e, nisso, o sujeito só é como negado, como pressuposição negada, e, assim, como contradição de ser e não ser. Enquanto nas formas pré-históricas pré-capitalistas a negação do predicado é limitação do sujeito, de sua infinidade ("o homem é o grego"), na forma pré-histórica capitalista, a relação entre sujeito e predicado é "uma relação contraditória", o predicado encerrando um "infinito negativo" (1983/1987a, p. 46). Desse modo, os juízos "a liberdade é a liberdade burguesa", a "propriedade é a propriedade burguesa" sofreriam uma interversão total porque o predicado põe a negação completa do sujeito: "a liberdade é a nãoliberdade", "a propriedade é a não-propriedade".

No entanto, o que vale para os pressupostos (homem, liberdade, propriedade) no capitalismo não se aplica ao capital, capaz de ser pressuposição e posição, sujeito e predicado, de sorte que o juízo sobre o capital não é um juízo de reflexão, mas "juízo do sujeito" (1987a, p. 20): os predicados do capital (dinheiro, mercadoria) não são negações dele enquanto sujeito. "Em se tratando de um sujeito no sentido ontológico pleno, o sujeito 'capital' não deve passar nos predicados 'mercadoria' e 'dinheiro'. O capital deve ser posto como igual ao capital (isto é, como sujeito)" (1983/1987a, p. 31). Ora, porque o capital é sujeito em seu movimento de pôr-se a si mesmo e fazer de suas pressuposições posições de si mesmo - e só nesse movimento ele é rigorosamente sujeito -, aqueles pressupostos, normativamente carregados, se intervertem nos contrários.

É o que se mostra em $O$ capital quando passamos da esfera da circulação e da produção simples para a teoria da reprodução e da acumulação. Com isso, tudo que formava a autocompreensão da sociedade burguesa, fincada na esfera da circulação (novamente: liberdade, igualdade, propriedade, contrato, equivalência etc.), é negado no movimento mesmo do capital como sujeito pleno:

A ideia de que o operário "encontra" no mercado o capitalista e lhe vende livremente a sua força de trabalho como qualquer vendedor vende a sua mercadoria aparece agora como uma ilusão da circulação. Na realidade, o operário e o capitalista são constantemente (re-)criados e "reunidos" pelo próprio movimento do capital, e é assim o movimento do capital que, reproduzindo o operário enquanto operário, 0 obriga a vender cada vez a sua força de trabalho. E mais do que isto. A "redução a uma aparência" provocada pela continuidade do processo não atinge apenas a liberdade do contrato: ela concerne à própria ideia de que há uma troca de equivalentes. É através da continuidade propriamente que o capital interioriza os seus pressupostos e elimina a sua dependência em relação ao seu ponto de partida. (...) Assim, não há mais equivalentes nem a rigor troca, mas apropriação sem equivalente do trabalho alheio. (...) Uma volta do capital ou cada volta do capital obedece à lei de apropriação ou de propriedade das economias mercantis, lei segundo a qual a apropriação dos produtos se faz pela troca de equivalentes e depende, em última instância, do trabalho próprio. Mas a repetição das voltas do capital - e portanto o cumprimento reiterado da lei de apropriação pelo trabalho e pela troca de equivalentes - interverte esta lei na lei de 
apropriação capitalista, apropriação sem equivalente do trabalho próprio (Fausto, 1983/1987a, 48). ${ }^{8}$

De acordo com Ruy Fausto, portanto, a circulação de mercadorias, pressuposto do desenvolvimento do capitalismo, é interiorizada pelo capital, de modo que todos os princípios normativos delas são postos e ao mesmo tempo negados no seu movimento como sujeito. Não se pode perder de vista, porém, que essa negação é também uma autonegação, uma vez que a lei da troca de equivalentes, e tudo o que ela comporta, é reiteradamente cumprida para chegar à sua interversão. A liberdade burguesa se torna a "liberdade do capital", a propriedade privada burguesa, a "propriedade do capital" sobre o proprietário individual etc., porque constituem em parte as condições para o vir a ser do capital como sujeito.

Dessa maneira, a crítica que Ruy Fausto vê em operação no texto marxiano é de tal ordem que não basta verificar a contradição entre a regra, o critério, a normatividade enfim defendida na formação social em questão, de um lado, e sua efetividade como um desmentido. Nesse aspecto, não sairíamos, como quer Rahel Jaeggi, de um modelo de crítica interna que se limita a comparar a norma e o real para mostrar a insuficiência na realização do normativo. Pelo contrário, trata-se de conferir como o normativo atua na efetividade, é eficaz, de modo que ele coopera também para aquela insuficiência ou contradição. Segundo Jaeggi, Marx não se vale apenas de uma mera comparação entre o que é normativamente afirmado nas ideologias burguesas, como a liberdade e a igualdade, e a realidade de não liberdade

80 texto marxiano que serve de suporte para esse discernimento sobre tal lógica de interversão se encontra no capítulo 22 do primeiro tomo de $O$ capital: " na medida em que cada transação singular corresponde continuamente à lei da troca de mercadorias, o capitalista comprando constantemente força de trabalho, o trabalhador vendendo-a constantemente, e queremos até mesmo supor que por seu valor real, a lei da apropriação ou a lei da propriedade privada se interverte [umschlagen] manifestamente, por meio de sua dialética própria, interior, inevitável, em seu contrário direto. A troca de equivalentes, que aparecia como a operação originária, girou de tal modo que apenas em aparência se troca quando primeiramente a parte do capital trocada por força de trabalho é somente uma parte do produto do trabalho alheio apropriado sem equivalente e, em segundo lugar, tem de ser não apenas suprida pelo produtor, pelo trabalhador, mas suprida com um novo excedente. A relação de troca entre capitalista e trabalhador torna-se, portanto, apenas uma aparência pertencente ao processo de circulação, mera forma que é alheia ao próprio conteúdo e apenas o mistifica. A compra e a venda constante da força de trabalho é a forma. 0 conteúdo é que o capitalista vende reiteradamente uma parte do trabalho alheio já objetificado, de que ele se apropria incessantemente sem equivalente, por um quantum maior de trabalho vivo. Originariamente, o direito de propriedade pareceu-nos fundado sobre o trabalho próprio. Ao menos, essa suposição tinha de valer, uma vez que apenas se contrapunham os possuidores de mercadores em pé de igualdade, uma vez que o meio para a apropriação da mercadoria alheia apenas é a alienação da mercadoria própria, e a última apenas é produzível por meio do trabalho. Propriedade aparece agora, do lado do capitalista, como o direito de se apropriar do trabalho alheio não pago ou seu produto, da parte do trabalhador, como impossibilidade de se apropriar de seu próprio produto. A divisão entre propriedade e trabalho torna-se a consequência necessária de uma lei que aparentemente partia de sua identidade. Por mais que o modo de apropriação capitalista parece golpear na cara das leis originárias da produção mercadoria, ele de modo algum surge da violação, mas, ao contrário, da aplicação dessas leis" (MEW 23, p. 610). 
e a desigualdade sociais produzidas pela sociedade capitalista. Mais importante seria a demonstração do funcionamento efetivo desses princípios, uma vez que eles se tornam mecanismos de produção do seu oposto, a liberdade levando à dependência mais cruel (Jaeggi, 2014, p. 285; cf. Zanvettor, 2020, p. 71; Repa, 2016).

Nos termos de Ruy Fausto, a posição da norma gera as condições de sua interversão completa. No entanto, por conta da relação entre posição e pressuposição, ele pode discernir também por que se pode falar que a liberdade burguesa é não liberdade já no ato do juízo, algo que parece escapar ao conceito de crítica imanente proposto por Jaeggi. Falta a este uma noção de posição que se entrelaça necessariamente com os pressupostos que ela nega, o que implicaria dizer que lhe falta ainda um conceito de totalidade em que o posto se enreda necessariamente. As condições de significação da posição excedem, como veremos, tudo que o posto pode exprimir por conta própria. Assim, ao perseguir-se de maneira estrita o conteúdo da posição no predicado revela-se a lógica da negação do pressuposto no sujeito. 0 posto nega o pressuposto (a liberdade é liberdade burguesa) tanto quanto nega a si mesmo (a liberdade burguesa é liberdade do capital). É em virtude do conteúdo normativo dos predicados postos que se nega enfim a liberdade, a propriedade, como sujeitos, de modo que se pode acrescentar: "mantendo a ideia de liberdade e the dando um conteúdo (um predicado) que contradiz a ideia de liberdade, ele [Marx] não faz senão reproduzir no nível da expressão a contradição real da liberdade burguesa" (1983/1987a, p. 52). A liberdade posta não pode significar a liberdade se não tem uma ligação com a ideia de liberdade pressuposta. Daí que a liberdade formal mais estreita não pode ser enunciada se não com a remissão intrínseca, embora negativa, com essa totalidade dos seus pressupostos, incluindo aí a igualdade e a propriedade.

No entanto, a ideia de "verdadeira liberdade" não seria aqui uma introdução indevida, exigida pelo sentido "político" que seria na verdade o fulcro da contradição no sentido “lógico" ("a liberdade burguesa não é a verdadeira liberdade”, a "liberdade burguesa é a não liberdade”)? Dizer que a liberdade burguesa contradiz a verdadeira liberdade e a si mesma não significaria, em última instância, preencher de maneira bem mais positiva a "pressuposição" do que o sentido político da "não posição" pretende estabelecer? Se, a rigor, não é dada nenhuma outra possibilidade crítica que o "pensamento que dá livre curso à interversão, que se deixa levar por ela” (1983/1987a, p. 55), o que autoriza pressupor a ideia de liberdade, de homem, de propriedade etc.?

II

Em termos ligeiramente distintos, a pergunta não é estranha ao projeto faustiano de investigar e reconstituir o sentido da dialética: 
O discurso dialético marxista “nega” os princípios e os transforma, assim, em pressupostos. Este é o ponto de partida de toda leitura dialética. Entretanto, pelo próprio fato de que os "princípios" permanecem - pressupostos embora -, o discurso posto se manteria talvez preso a eles. Se a hipótese é verdadeira, é como se a "negação" dos fundamentos não alterasse o conteúdo deles (1987a, p. 12).

Dessa perspectiva, Ruy Fausto teria que ceder muito mais à tese humanista do que a postura da não posição pretende circunscrever - e, consequentemente, também se afastar da via da crítica imanente até agora perseguida.

Não caberia reconstituir aqui todos os meandros da análise de forma que essa questão sobre a aderência do conteúdo dos pressupostos acaba impondo e que tem como quadro maior a reconstituição da apresentação marxista da história e o desdobramento da teoria dialética dos juízos ou dos enunciados, com o objetivo de abrir um caminho para pensar o processo de constituição do sujeito pressuposto. Um ponto desse conjunto complexo e inacabado é particularmente produtivo para o propósito de sustentar um conceito de crítica imanente em Marx: a ideia de possibilidade objetiva ou real. Pois por meio dela se compreende que a posição não simplesmente nega a pressuposição; ela institui um conjunto de possibilidades objetivas que sustentam a sua própria significação. E somente na medida em que esse todo é completamente negado, como a dinâmica capitalista instiga, a posição se contradiz inteiramente.

O âmbito teórico em que essas conjunções se desdobram é dado com o aprofundamento faustiano da concepção dialética da significação, segundo a qual todo conceito rigoroso deve acolher uma zona de sombra, um halo obscuro, para poder significar o objeto. A pressuposição é justamente aquela categoria que deve dar conta desse espaço de obscuridade constitutiva, não tanto como o não dito mas, antes, como a junção do dito e não dito: “(um certo) implícito - não dito 'afetado' de dito, ou então como (um certo) explícito - dito 'afetado' de não dito”; portanto, “o campo das pressuposições é um espaço de contradição" (1987b, p. 152). Nessa "fenomenologia da obscuridade" que a dialética comporta, a significação passa a depender, de certo modo como o mundo da vida em Husserl, de um campo de pressuposições ou intenções discursivas implícitas que não podem ser preenchidas, determinadas e postas, sem destruir a própria significação. Não se trata, porém, de apenas pôr o pressuposto, de tornar explícito o implícito, mas de considerar que a posição, a explicitação, confere uma nova significação ao pressuposto, assim como a passagem do posto ao pressuposto confere-lhe outro sentido.

O jogo de pressuposição e posição não se constitui apenas como relação do implícito e o explícito, ele também retoma a distinção aristotélica de potência e ato tanto no universo subjetivo como no universo objetivo da significação. No universo subjetivo do discurso justamente porque, destinadas a evitar a contradição, as 
categorias de potência e ato mantêm-se no quase-contraditório (o "em um certo sentido" de Aristóteles), assim como aquelas de pressuposição e posição não se resumem em chocar-se contra o princípio da identidade, pois sua contradição não é da mesma ordem que dois postos contraditórios; a pressuposição é ela mesma contradição, é e não é, e, dependendo do juízo, a posição contradiz a pressuposição e a si mesma, como vimos acima.

Porém, é no universo objetivo da significação que a correlação com a distinção entre potência e ato é mais instrutiva e, em todo caso, mais decisiva, na medida em que o objeto regula a instância discursiva do sujeito:

A possibilidade que introduz a noção de potência é possibilidade objetiva. Há pressupostos objetivos. Pressuposição e posição são noções que valem também para o objeto. (...) O objeto que assim se desenha não é um objeto de puras atualidades. A noção de pressuposição introduz um universo em que não existe apenas "o que é o caso", em que existe mais do que "o que é o caso", mesmo se pela expressão se entender tanto o existente como o não existente. 0 mundo contém também 0 existente-não existente (Fausto, 1987b, p. 155).

0 mundo é mais do que é o caso, ele se constitui de possibilidades objetivas como pressupostos do que é posto e, nesse sentido, o não existente diz sobre o existente; além disso, como possibilidades objetivas de algum modo postas como pressupostas, e o existente diz sobre o não existente.

Porém, como mencionado, não é indiferente se o conteúdo é posto ou pressuposto. Mesmo significações inteiramente determinadas podem não ser postas, não ter existência alguma. O exemplo privilegiado nos estudos de Ruy Fausto é aquele dado na seção sobre o fetichismo da mercadoria, quando Marx ergue a questão de saber se outras formas de produção, diferentes daquela voltada à produção de mercadorias, seriam impregnadas de fetichismo. Embora Marx veja na organização do trabalho de Robinson Crusoé "todas as determinações essenciais do valor" (MEW 23, p. 91), afasta dela a fantasmagoria fetichista. "Marx supõe que a posição da coisa - e a posição da coisa é a existência (social) da coisa - é essencial para que ela seja o que é" (1983/1987b, p. 105). Todas as determinações da coisa podem estar presentes sem que a própria coisa esteja presente, ou seja, falta a "posição objetiva dessas determinações" (1983/1987b, p. 105). O objeto pode ser apenas determinado sem que, por isso, seja posto. 0 elemento da efetividade posicional é essencial para a significação do objeto. É por esse motivo que Ruy Fausto vai enxergar na "Setzung" marxiana a recuperação parcial da objeção hegeliana à crítica kantiana da prova ontológica. Se Kant considera que a posição do conceito nada acrescenta ao conceito da coisa, de modo que "o real, assim, não contém mais do que o meramente possível" (Kant, KrV B 627), para Marx, como para Hegel, o "conjunto das determinações não esgota o conceito. Mesmo plenamente determinado, o conceito não é ele próprio se 
não for posto" (Fausto, 1983/1987b, p. 106).

Em última instância, não há conceito sem a posição do conceito. Não há conceito sem sua efetividade, sem sua posição inscrita no real. Daí não deriva, porém, um primado da posição tal e qual. Ao contrário, abre-se a perspectiva segundo a qual a efetividade cria o espaço das possibilidades objetivas a partir da qual se reproduz. Surge "uma instância pressuposta que coexiste com o discurso posto. Nessa instância pressuposta, não está desenhada a História do homem, mas um espaço de possibilidades aberto em forma geral para o homem" (Fausto, 2002c, p. 192).

Essas possibilidades objetivas se mantêm como pressupostos, sendo e não sendo, necessários para o momento da posição, mas sem a explicitação clara no solo da efetividade. Não são meras possibilidades, indiferentes à posição efetiva e, por conta disso, também impotentes, por assim dizer. "Quando se fala em pressuposição, tem-se em vista uma situação em que a condição de sujeito tem um mínimo de efetividade, mesmo se formal” (Fausto 2002b, p. 114). Nesse aspecto, a pressuposição também opera (levando em conta as diferenças introduzidas pelas fases da préhistória e da história) na realidade posta. Os pressupostos objetivos projetam aquela "zona de sombra", sem a qual nada positivo pode significar no plano do discurso. Nesse aspecto, a posição depende dos pressupostos que ela mesma põe ou que são postos com ela. ${ }^{9}$ Por outro lado, a relação entre a posição e as pressuposições que se abrem como possibilidades objetivas não é pacífica:

O pressuposto não é sempre o objeto possível, mas é sempre o objeto "negado". A negação pode ser a ausência de posição, e nesse caso ela remete à possibilidade. Mas pode ser propriamente negação, “desatualização” do objeto posto pelo objeto posto. (...) O pressuposto será propriamente o espaço dos objetos "negados" pelo sistema no interior mesmo do sistema (Fausto, 1987b, p. 177).

A relação entre dois polos, o posto e o pressuposto, é contraditória no rigor do termo: negam-se constituindo-se um pelo outro.

Se retomamos o quadro das pressuposições estabelecido já no primeiro tomo de Marx: lógica e política, e seus exemplos, podemos dizer que o juízo de reflexão "a liberdade é liberdade burguesa" destaca no campo discursivo da significação aquela dependência objetiva do conceito posto, limitado, de liberdade que só pode significar algo como liberdade ao remeter a um sentido que é presente e ao mesmo tempo negado ("a verdadeira liberdade"). E porque a liberdade burguesa não pode senão

\footnotetext{
9 Porém isso não se daria sempre em Marx, já que nem todos os modelos marxianos de crítica, em correspondência com as diferentes apresentações da história, conferem o mesmo peso e qualidade à pressuposição. O Manifesto e a Ideologia alemã consideram as pressuposições como "representações comuns", "maneiras de dizer" ou ainda ideias produzidas, significações vazias. Tem-se aí um "imperialismo do discurso posto", a "falta de um verdadeiro discurso pressuposto", embora haja uma "espécie de pressuposição da pressuposição". Por sua vez, o modelo dos Grundrisse e d'O capital permitiriam uma coexistência dialeticamente contraditória entre o discurso posto e o pressuposto (Fausto, 2002b, p. 92 ss.).
} 
negar seu campo de pressuposições objetivas de maneira tal que essa dependência de significação é destruída, chega-se à interversão total: "a liberdade é não liberdade". A unilaterização do princípio normativo posto desencadeia a decomposição dos laços, mesmo que negativos, com o conjunto das pressuposições que, em seu todo, estrutura a possibilidade de dar significação a ele, e com isso ele desagua na total oposição a si mesmo.

Se essas considerações têm alguma validade, pode-se dar um passo adiante afirmando que o projeto de constituir o sentido da dialética toma em Ruy Fausto uma via que sustenta também o discernimento desse sentido como um modelo de crítica imanente em que o posto não é suficiente como se poderia estabelecer de início. Nessa conexão, as figuras da posição e da pressuposição permitem colocar no coração desse modelo, no nível da efetividade posta, relações de dependência de significação e negação que elevam aquela ideia inicial de comparar o princípio normativo com sua efetividade a um patamar mais complexo. Ao tomar ao pé da letra o posto, e ver aí, na dinâmica do capitalismo moderno, não importando por ora suas fases, as intervenções dos princípios normativos mais caros da sociedade burguesa, Ruy Fausto alarga, sem fugir do objeto, o campo da imanência: "Seria preciso introduzir uma imanência de uma outra 'ordem' (no sentido de 'potência')" (2002a, p. 61).

O posto abre com ele ou por meio dele um campo de pressupostos objetivos que sustentam sua significação, ao mesmo tempo em que os nega e os "desatualiza". As pressuposições, porém, mantém sua presença mesmo que (ou por ser) negada. Naquilo que o princípio normativo posto rompe, em razão de sua unilaterização, os elos de significação, ele desmorona no seu contrário. Ao mesmo tempo, porque as pressuposições estão sempre presentes, a crítica imanente estaria continuamente decifrando a emergência de novas posições capazes talvez de escapar à lógica da interversão, poderíamos dizer: de levar em conta sempre o que negam na ordem capitalista.

\section{Referências}

Adorno, Th. W. (2015). Para a metacrítica da teoria do conhecimento. Trad. Marco Antonio dos Santos Casanova. São Paulo: Unesp.

Adorno, Th. W./Backhaus, H. G. (1997). "Theodor W. Adorno über Marx und die Grundbegriffe der soziologischen Theorie”. In: Backhaus, H. G. Dialektik der Wertform. Freiburg: Ça ira.

Althusser, L. (1965/1979). A favor de Marx. Trad. Dirceu Lindoso. Rio de Janeiro: Zahar.

Arantes, P. E. (1994). Um departamento francês de ultramar. Rio de Janeiro: Paz e Terra.

Becker, M. (2018). On Immanent Critique in Hegel's Phenomenology. Hegel Bulletin, 
41(2), 224-246. DOI: https://doi.org/10.1017/hgl.2018.8.

Benhabib, S. (1986). Critique, Norm, and Utopia. A Study of the Foundations of Critical Theory. Nova York: Columbia University Press.

De Boer, K. (2012). “Hegel's Conception of Immanent Critique: Its Sources, Extent and Limit”, In: Boer, K. \& Sonderegger, R. (orgs.). Conceptions of Critique in Modern and Contemporary Philosophy. London: Palgrave Macmillan.

Fausto, R. (1983/1987a). “Dialética marxista, humanismo, anti-humanismo". In: Marx: lógica \& política. Investigações para uma reconstituição do sentido da dialética. Tomo I. São Paulo: Brasiliense.

Fausto, R. (1983/1987b). “Abstração real e contradição> sobre o trabalho abstrato e o valor”. In: Marx: lógica \& política. Investigações para uma reconstituição do sentido da dialética. Tomo I. São Paulo: Brasiliense.

Fausto, R. (1983/1987c). “Circulação de mercadorias, produção capitalista”. In: Marx: lógica \& política. Investigações para uma reconstituição do sentido da dialética. Tomo I. São Paulo: Brasiliense.

Fausto, R. (1983/1987d). “Notas sobre o jovem Marx”. In: Marx: lógica \& política. Investigações para uma reconstituição do sentido da dialética. Tomo I. São Paulo: Brasiliense.

Fausto, R. (1983/1987e). "Sobre o destino da antropologia na obra de maturidade de Marx (1968)". In: Marx: lógica \& política. Investigações para uma reconstituição do sentido da dialética. Tomo I. São Paulo: Brasiliense.

Fausto, R. (1987a). "Para uma crítica da apresentação marxista da história: sobre a sucessão dos modos de produção”. In: Marx: lógica \& política. Investigações para uma reconstituição do sentido da dialética. Tomo II. São Paulo: Brasiliense.

Fausto, R. (1987b) “Pressuposição e posição: dialética e significações 'obscuras””. In: Marx: lógica \& política. Investigações para uma reconstituição do sentido da dialética. Tomo II. São Paulo: Brasiliense.

Fausto, R. (1993). Dialética marxista, dialética hegeliana - O Capital e a Lógica de Hegel. Discurso, 20, 41-76. DOI: https://doi.org/10.11606/issn.2318-8863. discurso.1993.37956

Fausto, R. (2002a). “Hoje (introdução geral)”. In: Marx: lógica e política. Investigações para uma reconstituição do sentido da dialética. Tomo III. São Paulo: Brasiliense.

Fausto, R. (2002b). “A apresentação marxista da história: modelos”. In: Marx: lógica e política. Investigações para uma reconstituição do sentido da dialética. Tomo III. São Paulo: Brasiliense.

Fausto, R. (2002c). "Sobre o conceito de capital. Ideia de uma lógica dialética". In: Marx: lógica e política. Investigações para uma reconstituição do sentido da dialética. Tomo III. São Paulo: Brasiliense.

Giannotti, J. A. (1968/1980). “Contra Althusser”. In: Exercícios de filosofia. Petrópolis: Vozes.

Giannotti, J. A. (1965/1985). Origens da dialética do trabalho. Porto Alegre: L\&PM.

Löwy, M. (2012). A teoria da revolução no jovem Marx. Trad. Anderson Gonçalves. São Paulo: Boitempo. 
Habermas, J. (2014a). Para a reconstrução do materialismo histórico. Trad. Rúrion Melo. São Paulo: Unesp.

Habermas, J. (2014b). Técnica e ciência como 'ideologia'. Trad. Felipe Gonçalves Silva. São Paulo: Unesp.

Hegel, G. W. F. (1970). Phänomenologie des Geistes (Werke, III). Frankfurt am Main: Suhrkamp.

Hegel, G. W. F. (1970). Enziklopädie der philosophischen Wissenschaften im Grundriss I (Werke, VIII). Frankfurt am Main: Suhrkamp.

Hegel, G. W. F. (1970). Wissenschaft der Logik I (Werke). Frankfurt am Main: Suhrkamp. Jaeggi, R. (2014). Kritik von Lebensformen. Frankfurt am Main: Suhrkamp.

Kant, I. (1974). Kritik der reinen Vernunft I. (Werkausgabe III). Frankfurt am Main: Suhrkamp.

Marx, K. (1972). Das Kapital - Kritik der politischen Ökonomie I (MEW 23). Berlin: Dietz Verlag.

Marx, K. (2006). Ökonomische manuskripte -1857/58 (Mega-2, II/1). Berlin: Akademie Verlag.

Marx, K. (1970). "Briefe aud den Deutsch-Französichen Jahrbüchern" (MEW 1). Berlin: Dietz Verlag.

Nobre, M. (1998). A dialética negativa de Theodor W. Adorno: a ontologia do estado falso. São Paulo: Iluminuras/FAPESP.

Repa, L. (2011). Totalidade e negatividade: a crítica de Adorno à dialética hegeliana. Cadernos CRH, 24(62), 273-284. DOI: https://doi.org/10.1590/S010349792011000200004.

Repa, L. (2016). Reconstrução e crítica imanente: Rahel Jaeggi e a recusa do método reconstrutivo na Teoria Crítica. Cadernos de filosofia alemã: Crítica e modernidade, 21(1), 13-27. DOI: DOI: https://doi.org/10.11606/issn.2318-9800. v21i1p13-27.

Repa, L. (2019). A essência da crítica: sobre o limiar da crítica imanente em Hegel. Discurso, 49(2), 269-285. DOI: https://doi.org/10.11606/issn.2318-8863. discurso.2019.165623.

Zanvettor, R. (2020). A crítica imanente de Rahel Jaeggi: entre a ontologia pragmática e a dialética da história. Dissertação de Mestrado. Universidade de São Paulo. 